\title{
AVANÇOS E RETROCESSOS DA EDUCAÇÃO SEXUAL NO BRASIL: APONTAMENTOS A PARTIR DA ELEIÇÃO PRESIDENCIAL DE 2018
}

\section{AVANCES Y RETROCESOS DE LA EDUCACIÓN SEXUAL EN BRASIL: REGISTROS DESDE LA ELECCIÓN PRESIDENCIAL DE 2018}

\section{ADVANCES AND SETBACKS OF SEXUAL EDUCATION IN BRAZIL: APPOINTMENTS FROM THE 2018 PRESIDENTIAL ELECTION}

Paulo Rennes Marçal RIBEIRO ${ }^{1}$

Solange Aparecida de Souza MONTEIRO ${ }^{2}$

A Educação Sexual no Brasil teve, nos anos 1930, seu primeiro momento de intensa divulgação nos meios de comunicação, graças ao trabalho pioneiro de médicos que se interessaram por questões de sexo e sexualidade e que deram a cientificidade necessária para o debate na sociedade. Muitos livros foram publicados e muitas editoras conceituadas se empenharam para que obras de conceituados autores brasileiros e estrangeiros alcançassem várias edições.

As primeiras décadas do século XX acolheram as obras de José de Albuquerque, Antonio Austregesilo e Hernani do Irajá, dentre tantas outras, e possibilitaram que um grande número de leitores passasse a se interessar e compreender pelo fenômeno sexual.

José de Albuquerque fundou em 1933 o Círculo Brasileiro de Educação Sexual, objetivando levar a Educação Sexual a todo território nacional fundamentada em uma visão de Educação Sexual sob a perspectiva da sociologia, psicologia, criminologia e pedagogia (Felício, 2011).

Sobre José de Albuquerque, Felício disse que o médico

atuou durante a primeira metade do século XX, sendo considerado um dos precursores do projeto de educação sexual nacional voltada para a população. Este projeto tinha como objetivo geral prestar um serviço de instrução e esclarecimento no que tange aos assuntos de educação e higiene sexual, abordando questões biológicas, psicológicas e morais (FELÍ́CIO, 2011, p. 1).

\footnotetext{
${ }^{1}$ Universidade Estadual Paulista (UNESP), Araraquara - SP- Brasil. Docente do Programa de Pós-Graduação em Educação Sexual, e no PPG Educação Escolar. ORCID: <http://orcid.org/0000-0002-1552-5702>. E-mail: paulo.rennes@unesp.br

${ }^{2}$ Instituto Federal de Educação Ciência e Tecnologia de São Paulo (IFSP), Araraquara - SP - Brasil. Mestra em Processos de Ensino, Aprendizagem e Inovação. ORCID: <http://orcid.org/0000-0002-1640-0266>. E-mail: solmonteiro@ifsp.edu.br
}

RIAEE - Revista Ibero-Americana de Estudos em Educação, Araraquara, v. 14, n. esp. 2, p. 1254-1264, jul. 2019. E-ISSN: $1982-5587$. 
Reis e Ribeiro (2004) enunciaram os feitos de José de Albuquerque enquanto pioneiro da Educação Sexual, destacando não apenas sua vasta produção bibliográfica, mas também iniciativas que, na época, indicavam seu posicionamento além de seu tempo: por exemplo, criticava o desquite, que considerava discriminatório e prejudicial aos cônjuges, defendendo o divórcio em plenos anos 1930, que só foi aprovado em 1977; propunha a educação sexual pelo rádio; organizou eventos, proferiu palestras públicas, inclusive pelo rádio e instituiu prêmios anuais para o melhor livro publicado sobre educação sexual; e chegou a propor uma lei da responsabilidade sexual, que visava punir pessoas responsáveis por transmitir as na época denominadas doenças venéreas.

Ainda que os anos 1930-1950 tivessem sido palco de um discurso científico prósexual, não podemos deixar de mencionar que entre tantos autores havia diferentes visões sobre educação sexual, incluindo ideais higienistas, profiláticos, religiosos, que faziam parte da mentalidade médica, científica e educacional do Brasil de então.

O importante é que, ao falar de sexo, ao ouvir sobre sexo, ao ler sobre sexo, a parcela intelectual ou instruída da sociedade brasileira das primeiras décadas do século XX se abriu para a educação sexual que, nos anos 1960, foi efetivada em escolas do Rio de Janeiro, São Paulo e Belo Horizonte. Por outro lado, os anos 1960 foram protagonizados pela Revolução Sexual, o Movimento Hippie e o advento da pílula anticoncepcional, elementos essenciais que estimularam uma nova moral sexual. Uma descrição mais completa deste período pode ser encontrada em Bueno e Ribeiro (2018, p. 49-56), e em Bedin (2016) que comenta sobre a mentalidade favorável à educação sexual existente entre 1960 e 1968, mesmo com o Golpe de Estado de 1964.

Podemos considerar que a ação repressiva em relação à educação sexual ocorreu com o AI-5, de 1968, no entanto isto não significou que houvesse uma moralização exacerbada dos costumes ou uma proibição total e abrangente de se falar de sexo. Havia os espaços permissivos. Curiosamente distintos tanto em sua veiculação quanto na concepção que faziam do sexo e das atitudes e comportamentos sexuais, o cinema e as instituições científicas deram o respaldo e o estímulo necessários para que a sociedade brasileira continuasse a respirar os ventos da liberdade sexual, ainda que com algumas amarras e restrições.

O cinema, na década de 1970, com a produção das pornochanchadas e a exposição do $\mathrm{nu}$ (exceto o nu frontal, que continuava proibido), estimulava as fantasias sexuais e lançava ao estrelato atrizes como Vera Fischer, Nicole Puzzi, Aldine Müller, Matilde Mastrangi, Sandra Barsotti, Sandra Bréa, Helena Ramos, Zilda Mayo, Selma Egrei, Adele Fàtima, Zaira Bueno, Angelina Muniz, Monique Lafond e Patrícia Scalvi. 
Em 1975, a Editora Abril criou uma versão brasileira da revista americana Playboy, que recebeu o título de Revista do Homem porque o governo militar não admitia uma revista nas bancas com o nome Playboy, mas em 1978 já pôde ser publicada com o nome original.

Nos anos 1980, associações científicas ligadas à ginecologia, à urologia e à psicologia trazem de volta o discurso sobre sexualidade e comportamento sexual e lançam as bases da sexologia (ou da Segunda Sexologia, como definem Russo e Rhoden, 2011) que irão sustentar e fortalecer o conhecimento sexual no Brasil a partir dos anos 1980, culminando na ida desse saber sexual para as universidades, consolidado no surgimento dos grupos de pesquisa no final dos anos 1990 e início dos anos 2000. As universidades brasileiras se tornam, então, a fonte do conhecimento sexual no país e as responsáveis por uma intensa produção bibliográfica sobre sexualidade e educação sexual, e em uma fase posterior, também sobre os estudos de gênero.

É também do início da década de 1980 a volta da educação sexual às escolas, inicialmente com o aval e incentivo da Prefeitura Municipal de São Paulo e da Secretaria de Educação do Estado de São Paulo.

O que é interessante neste contexto de regime militar é que a repressão ocorria mais intensamente no nível político. Quando se tratava da moral e do sexual, havia uma repressão mais branda e uma tolerância para comportamentos, publicações e imagens que não fossem considerados extremos. Assim como em relação a obras que tivessem o beneplácito da ciência.

Em 1977, a Editora Abril Cultural publicou, em fascículos, a coleção Amar: $a$ realidade sobre a vida sexual, que Bedin (2016, p. 34-35) assim comentou:

A obra, fartamente ilustrada e didaticamente acessível ao grande público, mas também de conteúdo de interesse a profissionais da área, foi dividida em dois volumes com 40 capítulos, e o primeiro deles, que também foi o primeiro fascículo a sair nas bancas, tratou justamente da Masturbação. Seguiu-se os temas Menstruação, Orgasmo, Casamento, Disfunções Sexuais, Sexualidade na Infância, Educação Sexual, Adolescência, Aborto, Prostituição, dentre vários outros.

Vendida em bancas de jornal, a coleção foi prestigiada pelo próprio diretor-presidente da Editora Abril, Victor Civita, que fez a seguinte apresentação:

A coleção AMAR é resultado de anos de experiência clínica e estudos sobre o comportamento sexual humano. Com a colaboração de renomados especialistas das ciências médicas e sociais, os médicos brasileiros Haruo Okawara e Rogério B. Sawaya escreveram uma obra que responde, em linguagem simples e direta, as indagações fundamentais sobre a sexualidade do homem e da mulher. Ao publicar esta obra, colocando à disposição dos 
autores sua equipe e recursos editoriais, a Abril Cultural está convencida de que presta significativo serviço ao leitor brasileiro, facilitando-lhe o acesso a informações necessárias para a vida. Por meio de uma obra que discute sexo com seriedade e, sobretudo, com naturalidade. (OKAWARA; SAWAYA, 1977, p. 3)

Terminado o regime militar, a volta da democracia estimulou a liberdade de expressão e, consequentemente, falar de sexo não era mais proibido. Houve, de fato, uma intensa valorização do sexual e a sociedade brasileira visualizava explicitamente e experimentava novos comportamentos trazidos pela liberalização da sexualidade.

De 1990 a 2015 a sociedade brasileira lida com profundas mudanças de normas e padrões culturais ligados à sexualidade, absorve o surgimento e a consolidação dos estudos de gênero, e discute diferentes modos de lidar com a sexualidade e aceitar a diversidade. Ações governamentais efetivas incentivam o desenvolvimento de projetos e programas voltados para a igualdade entre homens e mulheres, o respeito à diversidade e o combate à homofobia. Em 1997, a partir dos PCN - Parâmetros Curriculares Nacionais, o governo federal reconhece a educação sexual como tema importante e urgente na escola brasileira. Em 2012 é criado o primeiro curso de Mestrado em Educação Sexual do país, na Universidade Estadual Paulista “Júlio de Mesquita Filho" - UNESP, na cidade de Araraquara, interior de São Paulo.

No entanto, a partir principalmente de 2015, um discurso anti-sexual e contrário às liberdades conquistadas assola o Brasil de norte a sul. Uma onda de conservadorismo estimulada por um fundamentalismo cristão exacerbado inicia uma cruzada contra atitudes, manifestações e discursos considerados contrários aos princípios ditos cristãos. Igualdade entre gêneros, diversidade sexual, homofobia, cidadania, liberdade de expressão são temas associados ao comunismo, à esquerda, ao petismo e passam a ser execrados por setores da sociedade que, até então ofuscados pela democracia, ganham força fazendo oposição ao então governo do Partido dos Trabalhadores. Conseguem eleger, em 2018, um presidente de extrema-direita afinado com o fundamentalismo cristão e, desde janeiro de 2019, as ações políticas do governo passam pelo crivo de uma nova moral que pauta as decisões a partir de princípios religiosos e avaliação subjetiva.

Neste contexto, o Dossiê "Sexualidade, gênero e educação sexual em debate" na RIAEE - Revista Ibero Americana de Estudos em Educação é uma oportunidade para que pesquisadores sérios e diligentes de conceituadas instituições universitárias publiquem seus estudos e pesquisas, mostrando para a comunidade acadêmica que o tema em questão continua consolidado e mantém sua primordial importância como campo de conhecimento e pesquisa em desenvolvimento. 
Curiosamente, em 2015, justamente o ano que consideramos ser o momento de desencadeamento das ações e discursos de repressão das diferentes formas de expressão da sexualidade, publicamos o primeiro Dossiê na RIAEE: "15 anos do Núcleo de Estudos da Sexualidade: de grupo de pesquisa a programa de pós-graduação", cujo editorial (RIBEIRO, 2015) contextualiza a trajetória e consolidação dos estudos e pesquisas desenvolvidas na UNESP em Araraquara.

Agora, quatro anos depois, com o dossiê "Sexualidade, gênero e educação sexual em debate" novamente se coloca em pauta os novos desafios enfrentados perante a onda crescente do discurso conservador, que se alastra não apenas no governo mas também em diversos setores da população. A relevância das discussões e da busca de manutenção das liberdades sexuais conquistadas passa, impreterivelmente, pela educação, aqui abordada em seu caráter emancipatório, vital tanto para a compreensão de uma realidade conturbada como a atual quanto para a manutenção e garantia de direitos conquistados e da inclusão e equidade dos diversos setores da população.

Este dossiê traz 19 artigos que tratam de diversos temas que a educação sexual enfrenta atualmente, tanto no ensino escolar como na expansão de suas abordagens e inclusão de temas e enfretamentos contemporâneos em seu arcabouço. $\mathrm{O}$ primeiro desses artigos intitulado "Considerações sobre a sexualidade e educação sexual de pessoas com transtorno do espectro autista", por Ana Carla Vieira Ottoni e Ana Claudia Bortolozzi Maia, faz uma revisão teórica abordando a sexualidade das pessoas com o transtorno anteriormente conhecido por Síndrome de Asperger, como a falta de informação, comunicação e preparado, tanto da família quanto dos instrutores muitas vezes podem, até mesmo, inviabilizar a sexualidade desse grupo, deixando-o mais vulnerável a abusos e situações de risco. O debate traz a luz o ensino eficiente da educação sexual para esse grupo de pessoas como uma ferramenta para um desenvolvimento satisfatório e seguro, além de ser um fator de diminuição em sua vitimização.

O segundo artigo escrito por Maria Fernanda Sanchez Maturana, Solange Aparecida de Souza Monteiro e Vagner Sérgio Custódio com o título de "Acessibilidade e inclusão de pessoas com deficiência física em ambientes de sexo pago", trata do acesso de pessoas com deficiência física um tipo de lazer ao qual, muitas vezes, aos olhos da sociedade eles não precisariam ter acesso. Buscando elucidar o tema tanto pela visão das garotas de programa e o que elas poderiam pensar sobre atender esse grupo de pessoas, assim como também tendo o ponto de vista de homens portadores de deficiência física e as barreiras que eles enfrentam para ter acesso a esse tipo de lazer, barreiras essas que vão muito além de apenas as limitações 
físicas e de acesso, trazendo a luz um preconceito social que muitas vezes, de forma silenciosa, impede o acesso das pessoas com deficiência física a esse tipo de lazer.

Como nome de "A produção da família no Brasil contemporâneo: uma análise de leis e descrições jurídicas", de autoria de Luciana Kornatzki e Paula Costa Ribeiro, o artigo trata, através de enunciados jurídicos e leis, da ampliação do conceito de família no Brasil, de como essa ampliação traz novas significações e novos arranjos para essa estrutura, como por exemplo o reconhecimento da conjugalidade homossexual, suscitando com isso também combate por parte de setores mais conservadores e tradicionais, criando grupos de resistência em prol da família nuclear, principalmente nos meios religiosos e políticos.

No quarto artigo deste dossiê, de título "Paternidade na adolescência: analisando seu significado, os desafios e consequências", os autores, Jéssica Daniele Fávaro, Andreza Marques de Castro Leão, Paulo Rennes Marçal Ribeiro e Luiz Fernando Zuin, discutem um assunto considerado pouco abordado sobre a paternidade adolescente, buscando identificar dentro do tema os significados, a relevância disso e as mudanças oriundas deste evento na vida destes adolescentes, relatando sua participação tanto durante o período de gestação quanto durante os anos iniciais das crianças e como eles mesmos definem seus papeis nesse cenário.

"A sexualidade infantil em destaque: algumas reflexões a partir da perspectiva freudiana" é o quinto artigo deste dossiê, de autoria de Ivonicleia Gonçalves Boroto e Regina Célia Mendes Sanatore, trazendo uma análise bibliográfica da obra de Freud, para discutir um dos principais conceitos propostos por esse autor: a sexualidade infantil. $\mathrm{O}$ artigo além de tratar de questões pontuais do autor, como a amnésia e a bissexualidade infantil, traz uma discussão sobre a necessidade de se diferenciar o conceito de sexualidade do de genitalidade, usualmente atribuído ao se falar sobre isso, e como este conceito gera confusões e interpretações errôneas que podem afastar educadores e a sociedade de um tema que deveria ser tratado com afinco e seriedade.

Os autores Marlon Jose Gavlik Mendes e Fátima Elisabeth Denari, em seu artigo "Deficiência e sexualidade: uma análise bibliométrica", tratam sobre a produção científica brasileira sobre a temática, selecionando e analisando o conteúdo de artigos que abordem a sexualidade de pessoas com deficiência. Demonstrando, que apesar de ser um assunto de grande interesse para pesquisadores e profissionais da educação especial, ainda prevalecem a desinformação e o preconceito sobre esse tema, um cenário preocupante em vista da realidade enfrentada por essas pessoas. 
No artigo "Jogos de poder e profissionalização docente: discutindo as subjetividades do feminino em sala de aula", escrito por Welson B. Santos, Wender Faleiro e Higor Júnior de Oliveira, diferenças social e historicamente construídas na educação brasileira são tratadas com o objetivo de identificar o porquê existe uma preponderância, e mesmo uma aceitação naturalizada, da mulher no exercício docente em sala de aula, frente a uma recusa para que os homens sejam aceitos da mesma forma. $\mathrm{O}$ artigo se constitui através de um levantamento histórico desde o período imperial e análise do material conseguido sob a ótica foucaultiana para elucidar essa clivagem.

O oitavo artigo deste dossiê intitulado "Marcas sociais de nossos tempos: gênero sexualidade e educação em âmbito escolar", foi escrito por Cristiane de Assis Lucifora, Fábio Tadeu Reina, Luci Regina Muzzeti e Renan Antônio da Silva e teve por base a dissertação de mestrado "A reprodução das desigualdades de gênero nos contos de fadas/maravilhosos como marcas circunscritas na Educação Infantil" que teve nas categorias de análise de Pierre Bordieu seu principal referencial teórico para tratar sobre como, ainda nos dias de hoje, as desigualdades se fazem presentes e como são colocadas ideias de superação que trazem as oportunidades para todos, isto feito através de uma estratégia teórico reflexiva alicerçada pela Teoria Crítica.

\section{Intitulado "O saber fazer docente em educação para sexualidade na educação}

básica: um paralelo entre Portugal e Brasil" o nono artigo deste dossiê das autoras Marilia Frasseto de Araujo, Celia Regina Rossi e Filomena Teixeira, teve por objetivo, através de uma comparação entre Portugal e Brasil e as respectivas legislações que regulamentam o ensino de educação para a sexualidades nesses países, analisar como os docentes das diversas áreas do saber, lidam com a construção e exercício dos saberes relativos à sexualidade em sala de aula. Além de buscar compreender, através de observação, entrevistas semiestruturadas e considerando a formação (inicial ou contínua) dos docentes, como eles pensam dever ser construída a educação para a sexualidade.

No artigo "Teorização em educação sexual a partir da grounded theory", escrito por Claudionor Renato da Silva, é abordada a possibilidade de uso da metodologia da grounded theory para gerar teorização na área da educação sexual e como o uso dessa metodologia poderia ser de auxílio para a formação inicial de pesquisadores nessa área, tanto em nível de graduação como de pós-graduação.

Florêncio Mariano da Costa-Júnior, Bettina dos Santos de Almeida e Rinaldo Correr, em seu artigo "Concepções sobre gênero e formação no campo da psicologia da saúde" fazem uma reflexão sobre como as questões de gênero tanto na atuação profissional quanto no 
ensino dos cursos de graduação poderão contribuir para a instrumentalização de novas práticas. Tendo por base como modelos de feminilidade e masculinidade são mantidos e reproduzidos de forma inadequada socialmente, os autores voltam seus olhares para os efeitos desses estereótipos na área da saúde e como isso pode influenciar o comportamento de homens e mulheres na busca por uma vida saudável.

O décimo segundo artigo deste dossiê "Saúde sexual da mulher lésbica e/ou bissexual: especificidades para o cuidado à saúde e educação sexual", dos autores Firley Poliana da Silva Lúcio, João Paulo Zerbinati, Maria Alves Toledo Bruns e Célia Regina Vieira de Souza-Leite, aponta como, ainda hoje, é escassa a produção de conhecimento voltada para a mulher lésbica e/ou bissexual e como isso faz com que esse seja um grupo de pessoas exposto a um maior risco quando pensamos em Infecções Sexualmente Transmissíveis (ISTs) e HIV/Aids. Esse estudo foi feito através de uma revisão integrativa a parte das bases de dados Scopus, Cinahl, Lilacs e Scielo e apontou para a necessidade de aumento de investimento em políticas de saúde pública e na qualificação de profissionais em educação sexual como estratégia de prevenção contra as ISTs e HIV/Aids.

O artigo de número treze apresentado neste dossiê é intitulado "Reflexões sobre as interfaces entre as ações formativas EDUSEX e as tecnologias digitais: um estudo de caso interepretativo-dialético", escrito pelas autoras Sônia Maria Martins de e Melo Mônica Wendhausen, traz um estudo de caso analisado através da hermenêutica dialética, que mostra reflexões sobre as ações formativas realizadas e experienciadas pelo grupo de pesquisa EDUSEX, através do uso de tecnologias digitais, tanto para a adaptação progressiva de modelos de formação e práticas de ensino aprendizagem, quanto para a criação de novos modelos pautados por esse novo patamar tecnológico. Este estudo traz como questionamentos guias: (a) Quais as ações formativas elaboradas pelo Grupo EDUSEX, mais especificamente relacionadas à tecnologia digital? (b) Quais as características dessas ações formativas e suas interfaces com a tecnologia digital?

A autora Teresa Vilaça traz em seu artigo "Metodologias de ensino na educação em sexualidade: desafios para a formação contínua" uma reflexão sobre as práticas de professores/as buscando a elaboração de linhas orientadoras para sua formação contínua em educação em sexualidade, pois esta muitas vezes é aplicada e implementada sem a devida preparação e referencial teórico. Através da análise das metodologias e das práticas dos professores, além da aplicação de uma entrevista semiestruturada foi possível determinar que a formação contínua de professores pode ser capaz de criar um aprofundamento sobre os temas/problemas interdisciplinares relativos à sexualidade humana, além de auxiliar os 
docentes a refletir sobre suas práticas, melhorando assim, o conhecimento pedagógico sobre esse conteúdo.

O próximo artigo tem por título "Base nacional comum curricular e diversidade sexual e de gênero: (des)caracterizações" e é de autoria de Caio Samuel Franciscati da Silva, Ana Paula Leivar Brancaleoni e Rosemary Rodrigues de Oliveira, faz uma Análise Textual Discursiva, buscando identificar na Base Nacional Comum Curricular as concepções sobre diversidade sexual e de gênero abordadas por esse documento que é um dos alicerces da educação nacional. Ao longo da investigação é observado um grande forco no caráter biológico dos temas relativos à sexualidade, porém aborda de forma adequada a diversidade sexual e de gênero, além de tratar de forma bastante superficial a questão dos direitos humanos.

Das autoras Ariane Crociari e Marcia Cristina Argenti Perez, o artigo intitulado "O que estamos estudando sobre gênero na educação infantil: as lacunas na formação docente" traz uma abordagem bibliográfica sobre o tema dos estudos de gênero tanto pelo viés da educação infantil quanto da formação dos profissionais da educação. Além de apontar para uma falta de preparação do profissional docente para lidar com assunto da sexualidade, também observa que ainda existem muitas lacunas nas pesquisas do tema, quando focando na Educação Infantil. Ao abordar o tema através da bibliografia produzida sobre ele, também se pretende apontar nesse estudo elementos que podem vir a contribuir para a produção de conhecimento que venha a preencher parte das lacunas existentes na área atualmente.

O próximo artigo vai abordar a questão da trajetória de um docente da educação infantil, tanto de vida quanto profissional, se atentando para questões de gênero que podem envolver a docência, ele é intitulado "Ser professor na educação infantil: gênero e docência" e tem autoria de Fernanda Ferrari Ruis Sciotti, Marcia Cristina Argenti Perez e Luciana Ponce Bellido. O trabalho fez uso da observação participante e de entrevista semiestruturada, para analisar como a presença de um homem como professor da Educação Infantil é visto, os desafios e entraves que esse profissional pode enfrentar na carreira, além de também apontar ao final, como a presença de professores homens nessa fase da educação pode ajudar na desconstrução de concepções naturalizadas da mulher como a educadora de crianças pequenas.

$\mathrm{O}$ artigo "Binsex: uma proposta de bingo como recurso didático em abordagem crítica da educação sexual" é o penúltimo artigo apresentado no dossiê e é de autoria de Ediane da Silva e Yalin Brizola Yared. Este artigo trata de novas propostas didáticopedagógicas para promover o acesso a informação sobre os temas da sexualidade, trazendo 
como recurso específico o Binsex, que pautado na Declaração dos Direitos Sexuais e no paradigma da educação emancipadora visa superar a educação bancária, potencializando a prática pedagógica de docentes das Ciências Biológicas que tentem abordar os temas da educação sexual de forma criativa.

O último artigo deste dossiê é das autoras Claudia Pereira de Pádua Sabia e Tânia Suely Antonelli Marcelino Brabo e tem o título de "Relações de gênero no movimento dos trabalhadores sem-terra - MST: perspectivas a partir da concepção pedagógica do movimento" e faz parte de um projeto chamado "Concepções teórico-práticas de educação e trabalho no MST". O trabalho busca analisar se o processo educativo do MST tem contribuído para ações e discussões sobre o tema de relações de gênero, além de também tentar identificar essas relações no interior do movimento. O estudo foi desenvolvido através de pesquisas bibliográfica e documental, além de coleta de dados através de entrevistas semiestruturadas, tudo à luz de uma abordagem qualitativa do material coletado. Apesar de o trabalho apontar para alguns avanços conseguidos com muito esforço pelas mulheres, também evidencia que em questões de divisão do trabalho e oportunidades ainda existe um longo caminho a ser percorrido dentro do movimento.

Os artigos apresentados abordam das mais diversas maneiras o tema da educação sexual, trazendo discussões que podem complementar e apontar lacunas que ainda existem no arcabouço de conhecimentos que envolvem este tema, além de apontar para os desafios do passado, começa um prospecto dos novos desafios que a educação sexual pode vir a enfrentar, não apenas na educação escolar, mas em todas as esferas de convívio social. Esses trabalhos são construídos na expectativa de que, mesmo que existam os problemas a serem enfrentados e novos desafios a surgir, a consolidação de uma educação sexual eficiente no ensino brasileiro é um dos passos necessários para que muitos preconceitos sejam superados e que direitos e liberdades pessoais sejam respeitados e garantidos, formando assim uma sociedade mais justa e igual.

\section{REFERÊNCIAS}

BEDIN, R. C. A história do Núcleo de Estudos da Sexualidade e sua participação na trajetória do conhecimento sexual na UNESP. 2016. 154 f. Tese (Doutorado em Educação Escolar) - Faculdade de Ciências e Letras, Universidade Estadual Paulista "Júlio de Mesquita Filho", Araraquara, 2016. 
BUENO, R. C. P.; RIBEIRO, P. R. M. História da educação sexual no Brasil: apontamentos para reflexão. Revista Brasileira de Sexualidade Humana, v. 29, n. 1, p. 49-56, 2018.

FELICIO, L. A. Um projeto de Educação Sexual para o Brasil: o Círculo Brasileiro de Educação Sexual (1933-1945). Anais do XXVI Simpósio Nacional de História, 2011. Disponível em:

http://www.snh2011.anpuh.org/resources/anais/14/1300919582_ARQUIVO_TrabalhoparaAn puh(primeiraversao).pdf.

OKAWARA, H.; SAWAYA, R. B. Amar: toda a realidade sobre a vida sexual. São Paulo: Editora Abril Cultural, 2 v., 1977.

REIS, G. V.; RIBEIRO, P. R. M. A institucionalização do conhecimento sexual no Brasil. In: RIBEIRO, P. R. (Org.) Sexualidade e educação: aproximações necessárias. São Paulo: Arte \& Ciência, p. 27-71, 2004.

RIBEIRO, P. R. 15 anos do Núcleo de Estudos da Sexualidade: de grupo de pesquisa a programa de pós-graduação. Revista Ibero Americana de Estudos em Educação.

Araraquara, v. 10, n. esp., p. 1389-1393, 2015.

RUSSO, J.; ROHDEN, F. (Org.) Sexualidade, ciência e profissão no Brasil. Rio de Janeiro: CEPESC/IMS/UERJ, 2011.

\section{Como citar este artigo}

RIBEIRO, Paulo Rennes Marçal; MONTEIRO, Solange Aparecida de Souza. Dossiê: Avanços e retrocessos da educação sexual no Brasil: apontamentos a partir da eleição presidencial de 2018. Revista Ibero-Americana de Estudos em Educação, Araraquara, v. 14 , n. esp. 2, p. 1254-1264, jul. 2019. E-ISSN: 1982-5587. DOI: 10.21723/riaee.v14iesp.2.12701

Submetido em: 30/09/2018

Revisões requeridas: 20/02/2019

Aprovado em: 30/04/2019

Publicado em: 25/06/2019 